Journal of Fundamental and Applied Sciences

ISSN 1112-9867

Available online at

http://www.jfas.info

\title{
ECO-TECHNIQUE OF SEWER RENOVATION USING COMPOSITE SHELLS: STRUCTURAL ANALYSIS
}

\author{
B. Attaf \\ Expert in Composite Materials \& Structures Team Europe - European Commission \\ Representation in France
}

Received: 22 October 2011 / Accepted: 12 November 2011 / Published online: 31 December 2011

\begin{abstract}
An eco-technical renovation of the sewage system is developed in this paper; this technique involves incorporating into the existing sewer a series of jointed prefabricated sandwich or composite shells. The purpose of his study is to determine the structural shell deflection, the high displacement areas and to validate the non-failure criterion for each ply constituting the inner and outer laminate facings. The numerical results were obtained at low cost by using the finite element method. Studies have focused on structural analysis of a typical shell unit with an ovoid form (egg-shaped section) when it is subjected, during annular space filling operation, to pressure forces generated by wet concrete. To ensure the safety of the composite shell structure, Tsai-Hill criterion function is applied and results are presented for the most stressed plies.
\end{abstract}

Key words: sanitation; sustainable development; composite collector en composite; sandwich shell; finite element approach.

\section{INTRODUCTION}

In some large and older cities, the underground collectors of sewage were built with bricks and are now showing signs of ageing behaviour and fatigue [1-3]. This situation requires therefore particular attention to assess the sewer's structural state. In addition, designing ecologically sustainable sanitation network is ensured by a good choice of evacuation systems coupled with high quality standards [4-5].

Author Correspondence, e-mail: b.attaf@wanadoo.fr

ICID: 1020750 
Large underground drain-pipes are able to collect and remove wastewater and surface water from populated areas to sewage treatment works for water sustainability and advanced recycling (Fig. 1). But the inevitable leaks in the drainage system, mainly due to the ageing behaviour of such structures, the poor tightness and the fatigue phenomenon can pollute groundwater and therefore contaminate drinking water supplies and agriculture soils [6]. This environmental pollution can cause a number of risks to human health and the environment and becomes a source of several diseases such as diarrhea, typhoid, cholera, hepatitis, malaria [7].

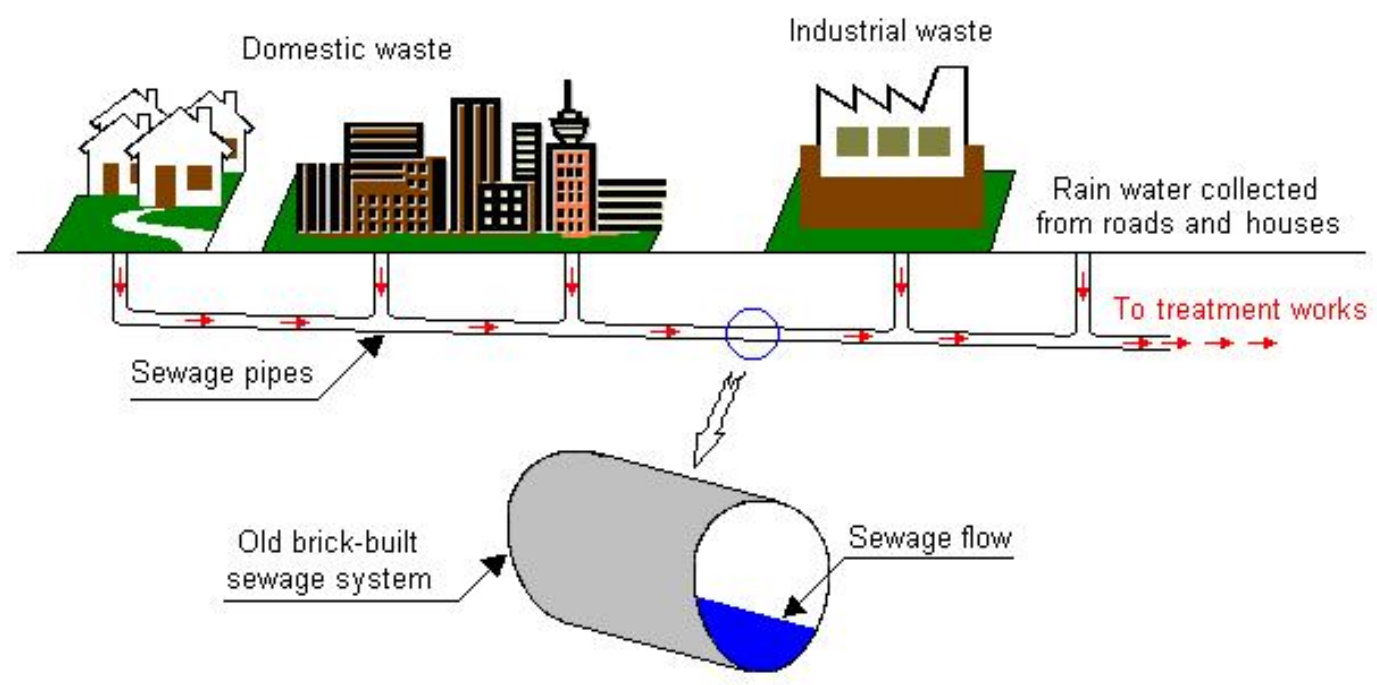

Fig.1. Sewage system

In order to overcome this problem and minimize or drastically reduce these risks, an innovative technique for the renovation of existing sewage systems is presented in this article. This technique involves incorporating into the existing sewer a series of jointed prefabricated composite shells [8]. The new shell cross-section is practically the same as the existing sewer with a small reduction in size. The reduction in the hydraulic crosssection is counterbalanced by the shell ultra-smooth surface which reduce friction to fluid flow [9]. In addition, the annular space (void) between the composite shell and the existing collector is filled with concrete $[8,10]$.

It should be noted that in the sanitation domain, the use of cross-section with an ovoid form (egg-shaped section) is highly recommended, because this shape prevents sedimentation phenomenon as a result of high-speed water with low flow in the narrow side of the collector (lower part of the shell). For that reason, a composite shell with an ovoid cross-section has been adapted to the current situation. Studies were concentrated 
on stress analysis of the sandwich shell structure when this latter is subjected, during annular space filling operation, to pressure forces generated by the wet concrete. These forces can have severe effects on the shell structure, where high stresses can develop.

\section{METHODOLOGY}

This investigation is oriented towards the study of the structural behaviour of the composite shell: determination of the shell deflection, high displacement areas, maximum stress concentrations and validation of the non-failure criterion for each ply constituting the inner and outer laminated facing using numerical modelling approach (i.e., finite element method).

\subsection{Shell structure and material}

The ovoid shell wall is a sandwich structure [11] separated by a thick lighter element called core: a plastic honeycomb with a thickness of $20 \mathrm{~mm}$. The inner and outer facing, with thickness of $5 \mathrm{~mm}$ each, are manufactured from glass-fibre laminates (Fig. 2). The total thickness $(H+2 e)$ of the sandwich shell wall is equal to $30 \mathrm{~mm}$.

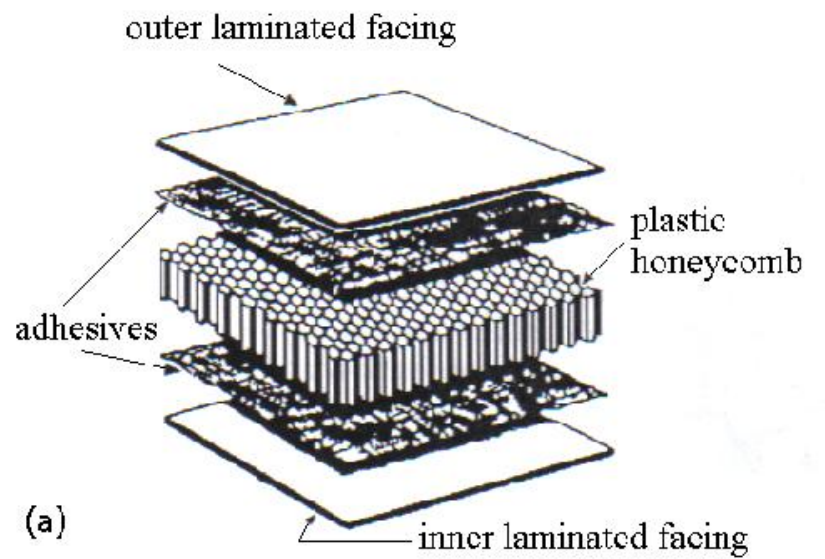

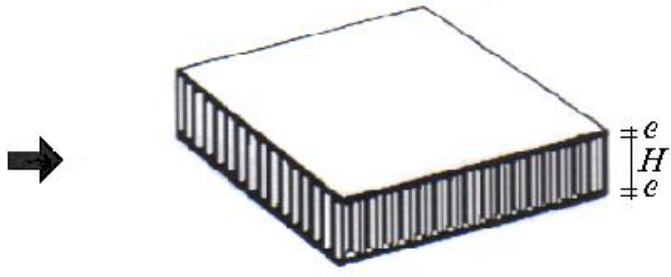

(b)

Fig.2. Sandwich structure constituting the wall of the ovoid shell: (a) exploded view; (b) adhesively assembled view

The laminated skin is made up of several layers of continuous strand mat $450 \mathrm{~g} / \mathrm{mm}^{2}$ based E-glass fibre and vinylester resin. The layers of mats are considered as quasiisotropic in the 1-2 plan. 


\subsection{Shell dimensions and annular space filling process}

In mathematics, an ovoid section is a surface shaped in the form of an egg and has only one axis of symmetry. The surface of an ovoid is defined in the coordinate system by the following equation:

$$
a(1+\alpha y) x^{2}+b y^{2}=1
$$

where $a, b$ are the lateral dimensions of the ovoid cross-section and $\alpha$ is a value that affects the shape of the bottom rounded area.

Figure 3(a) illustrates the principal dimensions of the composite shell. The internal height and width of the shell cross-section are $1.80 \mathrm{~m}$ and $0.75 \mathrm{~m}$, respectively. Each shell unit has a length of $1.12 \mathrm{~m}$. In order to increase the longitudinal shell stiffness, stiffeners with a thickness of $3 \mathrm{~mm}$ are incorporated into the sandwich structure along the ovoid circumference. The average distance between stiffeners is $0.28 \mathrm{~m}$. The stiffeners have the same mechanical properties as the inner and outer facing, i.e. $30 \mathrm{~mm}$.

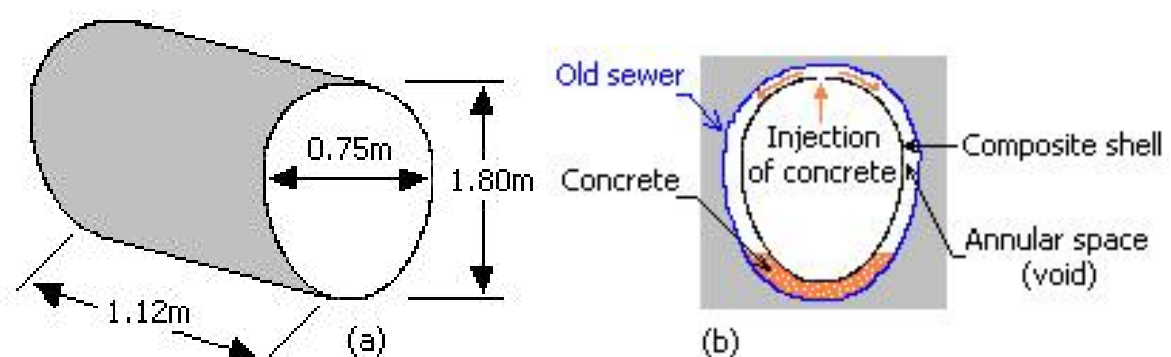

Fig.3. (a) Ovoid composite shell dimensions; (b) Annular space filling process

The annular space between the old brick-built sewer and the new ovoid composite shell is filled with liquid concrete (Fig. 2(b)). This latter is injected under pressure through holes (two per unit) drilled on the top of the shell. Removed sandwich plugs from holes are retained for future use. Once the filling operation is completed, holes are sequentially bunged with the retained plugs to prevent leakage of water inside the sandwich wall structure. To reduce the pressure forces generated by the wet concrete, the filling operation can be performed at different levels. 


\subsection{Lamination theory and constitutive relations}

When the out-of-plane shear deformation effect is taken into account, the constitutive relations for a general sandwich plate structure can be written in compact matrix form as $[12,13]$ :

$$
\left\{\begin{array}{l}
\{N\} \\
\{M\} \\
\{Q\}
\end{array}\right\}=\left[\begin{array}{ccc}
{[A]} & {[B]} & 0 \\
{[C]} & {[D]} & 0 \\
0 & 0 & {[F]}
\end{array}\right]\left\{\begin{array}{l}
\left\{\varepsilon^{0}\right\} \\
\{\kappa\} \\
\{\gamma\}
\end{array}\right\}_{x, y}
$$

For the case of identical facing, there is no bending-extension coupling $\left(B_{i j}=C_{i j}=0\right.$, $i, j=1,2,6)$. Therefore, the structural analysis of the static problem, which is initially described by five fundamental equations, can be reduced to three equations.

Difficulties inherent to transverse shear deformation, anisotropy of material, geometrical configuration of the shell and its boundary conditions constitute a complex and tedious analysis and this makes an exact mathematical solution impossible. To overcome these difficulties, finite element approach (FEA) is alternatively used $[14,15]$.

\subsection{Finite element modelling}

For symmetry reasons, only half of the shell structure is modelled. This technique can reduce the total number of elements and nodes required for modelling the structure, which saves time and allows faster computer processing. Thus, the appropriate boundary conditions (BC) for nodes located along the line of symmetry (i.e. $y$-axis) can be represented by the corresponding nodal displacement vector $\left\{u ; v ; w ; \theta_{\mathrm{x}}, \theta_{\mathrm{y}} ; \theta_{\mathrm{z}}\right\}^{\mathrm{T}}=$ $\{0 ; 1 ; 1 ; 1 ; 0 ; 0\}^{\mathrm{T}}$, where codes 0 and 1 denote fixed and free $\mathrm{BC}$, respectively.

\section{(a) Modelling of shell structure and stiffeners}

Using the finite element method, the half-shell physical model is divided longitudinally, transversely and vertically (for stiffeners) into a large number of elements. The four-node rectangular shell element is chosen as the element type for meshing the structure; this latter is modelled by 3034 elements and 5131 nodes. The internal stiffeners (I-beam element with two nodes) are discretized into 60 beam 
elements. Fig. 4(a) shows the final layout of the elements for which the half-shell structure was divided.

\section{(b) Modelling of static loads}

Static loads are due to the weight of the composite shell and the pressure forces generated by the wet concrete. The density of the concrete is taken to be $2500 \mathrm{~kg} / \mathrm{m}^{3}$. On the other hand, the maximum pressure forces are assumed to be $0.037 \mathrm{MPa}$ and 0.007 $\mathrm{MPa}$ at the bottom and the top of the shell, respectively. The finite element loading model is illustrated in Fig. 4(b).

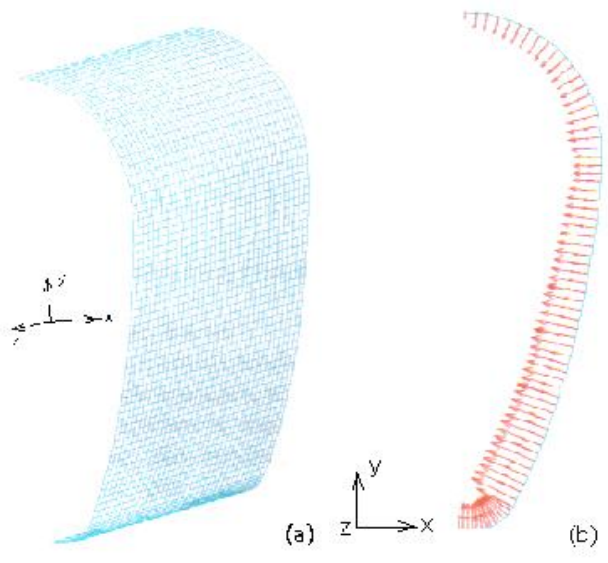

Fig.4. Finite element modelling: (a) discretization of the shell structure; (b) modelling of static loads

\section{(c) Modelling of boundary conditions}

When the annular space is filled with wet concrete, the shell structure can float since no constraints are applied on it and the system becomes unstable (free boundary conditions). To overcome the stiffness matrix singularity problem (the determinant is equal to zero; i.e. $[K]=0$ ) when using the finite element approach, the shell structure is restrained at the top and bottom with concrete wedge blocks, placed between the composite shell and the existing sewer system (see Fig. 5(a)). Besides the symmetry conditions, the boundary conditions associated to the wedges and the half-shell system are illustrated in Fig. 5(b). 


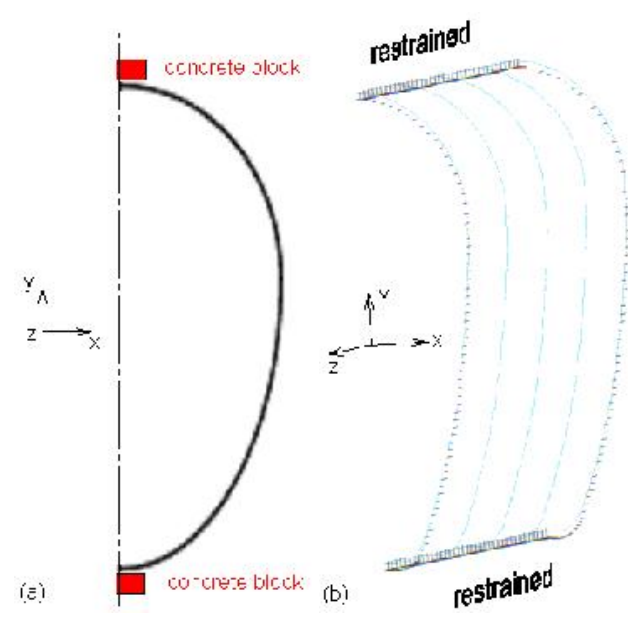

Fig.5. (a) Concrete wedge blocks to overcome the free boundary conditions; (b)

Modelling of half-shell boundary conditions

\section{RESULTS AND DISCUSSION}

\subsection{Structural shell deflection}

The structural half-shell deflection results are presented in Fig. 6(a). The deformed shape will indicate the areas of maximum displacements where fibre orientation and longitudinal stiffeners could be tailored to reduce the high displacements [16]. As it can be seen from Fig. 6(b), the maximum displacement along the $x$-axis is occurring internally and is about $33 \mathrm{~mm}$ (blue area in Fig. 6(b)).

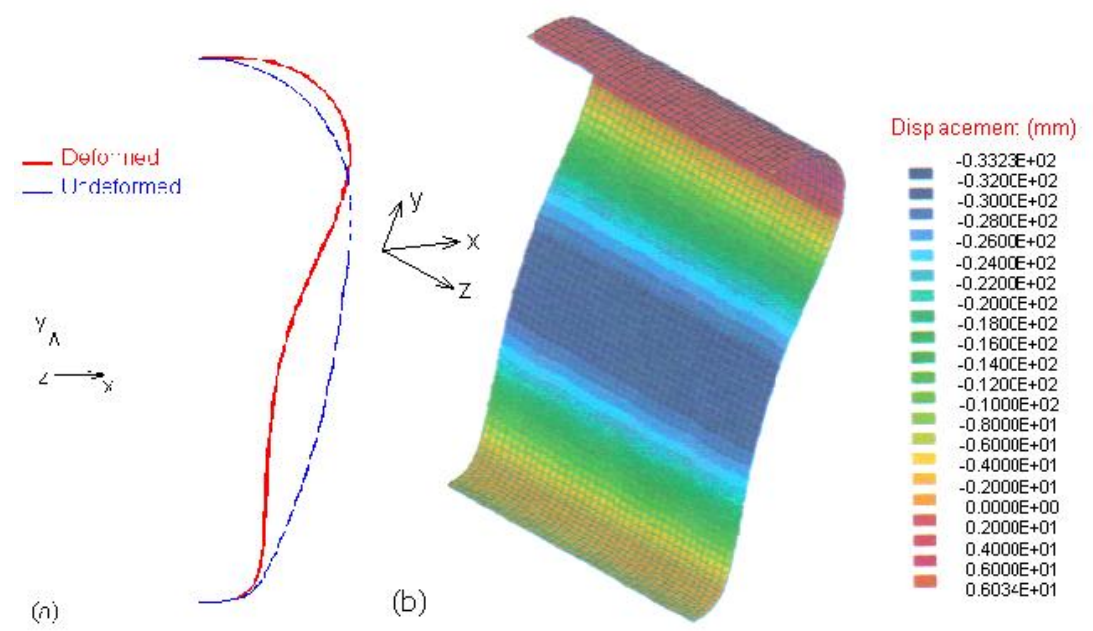

Fig.6. Structural deflection of the composite half-shell structure: (a) typical deformed shape; (b) high displacement areas 


\subsection{Failure analysis}

The non-failure criterion of each ply constituting the inner and outer laminated facing is checked using the Tsai-Hill criterion function, given by the following equation $[3,4]$ :

$$
\left(\frac{\sigma_{1}}{X}\right)^{2}+\left(\frac{\sigma_{2}}{Y}\right)^{2}+\left(\frac{\tau_{12}}{S}\right)^{2}-\frac{\sigma_{1} \sigma_{2}}{X^{2}}=1
$$

Where, $X$ is the maximum tensile (compressive) failure stress in the 1 -direction, $Y$ is the maximum tensile (compressive) failure stress in the 2-direction and $S$ is the maximum shear failure stress in the 1-2 plane.

Failure areas are those where the criterion value exceeds 1 (100\%). By applying TsaiHill criterion, it can be seen from Fig. 7 that the maximum values are approximately 86\% (red areas in Fig. 7(a)) and 65\% (red areas in Fig. 7(b)) for the inner and the outer facing, respectively. These critical values are occurring in the most highly stressed plies forming the laminated facing.
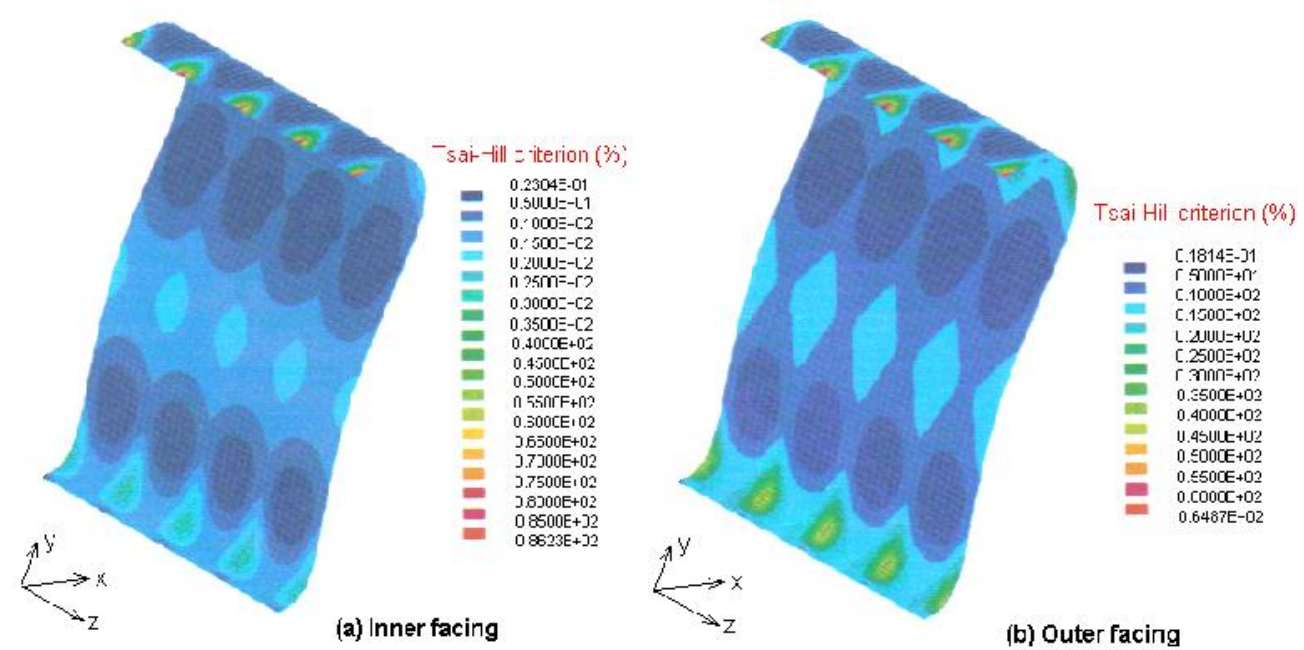

Fig.7. Tsai-Hill failure criterion for the most highly stressed plies: (a) inner facing; (b) outer facing

The finite element analysis of the ovoid composite shell structure has allowed us to locate areas of high displacements and those susceptible to failure. In addition, it was 
confirmed that the value of failure does not exceed $100 \%$ when applying the Tsai-Hill criterion to the most highly stressed plies forming the inner and the outer laminated facing. Therefore, the presented shell structure is set up to be safe and able to withstand pressure forces generated from the wet concrete to which is exposed during annular space filling operation.

This preliminary investigation has provided a better understanding of the composite shell structural behaviour and has helped us to identify the different areas to be carefully examined. Thus, high displacement areas can be reduced or eliminated, if one or a combination of the following techniques is used:

1) minimization of the maximum structural deflection by placing inside the shell and at the high displacement areas wooden beams on both sides of the shell wall, preventing deformation from occurring. These beams will be removed once the concrete is dry;

2) reduction of the structural deflection by injection of concrete in several phases with different levels, thereby reducing the concrete pressure forces and consequently the high stresses and deformations.

The latter technique is expensive in terms of time-saving and less effective if injection is made for a long sewer with a significant slope. In addition, maximum structural deflection can be reduced if glass-fibers are orientated precisely in the most effective position with better choice of stacking sequences.

\section{CONCLUSION AND FURTHER WORK}

This numerical approach reinforces the fact that structural investigation of composite shell behavior must not depend upon one analysis procedure only. Comprehensive modeling of a finite element solution from an experimental procedure should be undertaken before parameter studies are made. This will ensure a safe structure that will fulfill an efficient structural performance coupled with economic design.

In addition to the static problem, several issues must be considered and examined; among them, the influence of water and other liquid/fluid agents on the material properties. The layer of gel-coat used to protect fibres from external environment must have good physical and chemical characteristics, because the risk of leakage is the main factor that accelerates the degradation, ageing behaviour and reduction of the shell structure life-time. Therefore, further studies and investigations on the behaviour of gel- 
coat in contact with liquid and/or fluid agents still required in the short and long term before shell qualification process is performed.

\section{REFERENCES}

[1] Ugarelli R. et al. Importance of investment decisions and rehabilitation approaches in an ageing wastewater pipeline network:a case study of Oslow (Norway), Water Science and Technology. 2008, 58(12), 2279-2293.

[2] RERAU. Projet National Réhabilitation des Réseaux d'Assainissement Urbain: Restructuration des collecteurs visitables. Guide Technique, Vol.1, Tec \& Doc. Lavoisier, Paris, 154 (2002)

[3] RERAU. Projet National Réhabilitation des Réseaux d'Assainissement Urbain: Restructuration des collecteurs visitables. Guide Technique, Vol.2, Tec \& Doc. Lavoisier, Paris, 2004, 250 (2004)

[4] Sharma A. K. et al. Sustainable sewerage servicing options for peri-urban areas with failing septic systems, Water sciences and technology. 2010, 62(3), 570-585.

[5] Lehn H. Technologies for sustainable urban water management-dissolving the antagonism between urban comfort and hygienic pollution of urban environs. Proceedings of the Int, Symposium on Water landscapes, Sydney. 2009, 59-70.

[6] Lee E. J. and Schwab K. J. Deficiencies in drinking water distribution systems in developing countries, Journal of water and health. 2005, 3(2), 109-127.

[7] Norman et al. Effects of sewerage on diarrhoea and enteric infections: a systematic review and meta-analysis, Lancet. Infection diseases. 2010, 10(8), 536-544.

[8] RERAU 4. Réhabilitation des collecteurs visitables par éléments préfabriqués. Institut pour la recherche appliquée et l'expérimentation en génie civil (http://irexweb.pagesperso-orange.fr/rerau_4.htm) (2010)

[9] Marriott M. J. The hydraulic characteristics of ovoid sewers, Meeting of the Institution's East Anglia Branch. 1996, 10(5), 365-368.

[10] Thépot O. 2001, The structural design of non-circular linings. Underground Infrastructure Research: Municipal, Industrial and Environmental Applications. Edited by Knight \& Thomson, Swets \& Zeitlinger, Lisse, 65-74p.

[11] Attaf B. On the free vibration of honeycomb sandwich plates, IABSE Symposium, Rio de Janeiro. 1999, 292-293. 
[12] Jones R. M. 1999, Mechanics of composite materials, 2nd ed, Taylor \& Francis, Philadelphia.

[13] Saarela O. Computer programs for mechanical analysis and design of polymer matrix composites, Prog. Polym. Sci. 1994, 19, 171-201.

[14] Kesteloot S. et al. Etude numérique pour l'optimisation de la réhabilitation d'ouvrages d'assainissement à l'aide de composites, Mécanique \& industries. 2006, 6, 605-614.

[15] Yang T. Y. 1986, Finite element structural analysis, Prentice-Hall, New Jersey.

[16] Attaf B. and Hollaway L. Vibrational analyses of glass reinforced polyester composite plates reinforced by a minimum mass central stiffener, Composites. 1990, 21(5), 425-430.

How to cite this article

Attaf B. Eco-technique of sewer renovation using composite shells: structural analysis. $\mathbf{J}$ Fundam Appl Sci. 2011, 3(2), 144-154. 